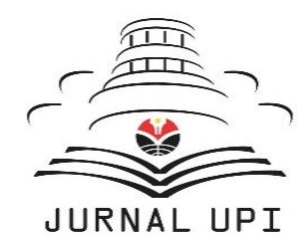

INDONESIAN JOURNAL OF APPLIED LINGUISTICS

Vol. 10 No. 2, September 2020, pp. 349-358

Available online at:

https://ejournal.upi.edu/index.php/IJAL/article/view/28602

https://doi.org/10.17509/ijal.v10i2.28602

\title{
Improving students' arguments through collaborative learning
}

\author{
Dona Kumala Shinta and Filia \\ Department of Linguistic, Faculty of Humanities, Universitas Indonesia, Depok, West Java, Indonesia
}

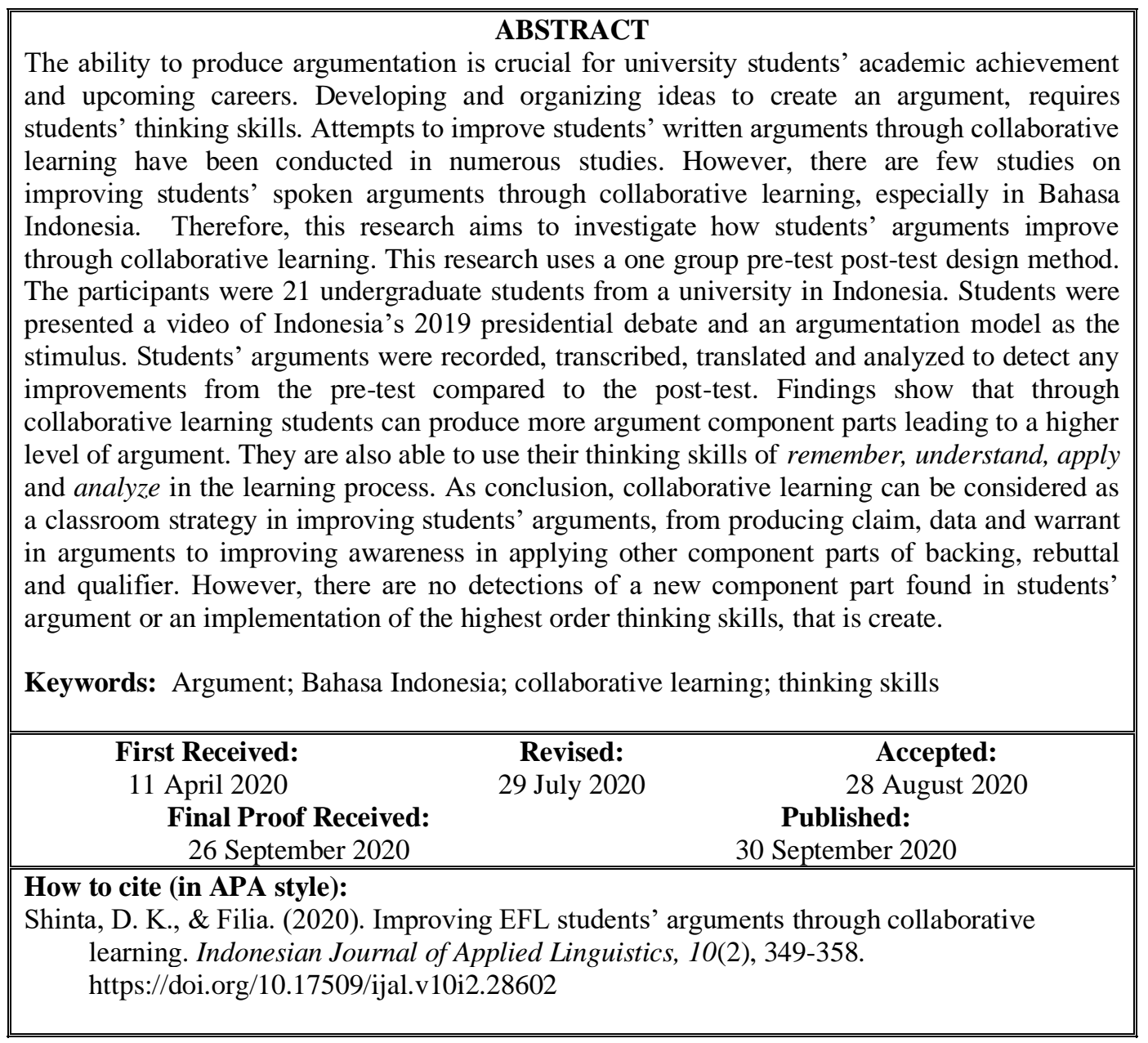

\section{INTRODUCTION}

Producing arguments orally, as well as in written texts, is an essential skill needed by students in a learning process. In higher education setting, university students are demanded to deliver their standpoints upon a certain issue in oral communication through logical reasonings and supporting evidences by using their thinking skills. However, studies reveal that though students are able to deliver claims, they are not supported by reasons or evidences which is considered crucial in generating a strong argument (Skoumios \& Hatzinikita, 2008 cited in Syerliana et al., 2018). In Indonesia, studies found that students in senior high school lack of argumentation skills (Amielia et al., 2018; Syerliana et al., 2018). This can be seen through students' answers containing of less foundations or sufficient evidences to back up their claims. Thus, students' weak ability in constructing arguments will intervene their academic achievement in a university if not guided by teachers on how to generate an argument. As said by Widodo et al. (2016) that reasoning skill is considered important because it may give contributions to students' learning quality; thinking clearly and critically.

In the teaching and learning process, teachers have been focusing on how to improve students'

\footnotetext{
* Corresponding Author

Email: dhona.malshia@gmail.com
} 
written arguments by giving students certain treatment and approaching students to work together in groups. Toulmin's model of argument has been widely used by teachers to analyze students' argumentative skills as well as to guide students on component parts needed to generate a high quality of argument in giving reasonings of a statement, such as in science class (Simon, 2008). Toulmin's set of argument consists of claim, data, warrant, backing, qualifier and rebuttal (Toulmin, 2003). Applying these component parts in an argument, students are intended to improve their argument quality. This model has given positive improvements in students' arguments in writing skills (Kristiyanti et al., 2018; Suhartoyo et al., 2018). Furthermore, learning collaboratively also gives the opportunities for students to activate their higher order thinking skills or critical thinking when analyzing and evaluating their peer's work in the process of draft writing.

Meanwhile, facilitating students with questions may also enhance students' thinking skills in delivering responses orally by creating interactions in class (Chen, 2016). However, based on the researcher's personal observation and some studies (Chen, 2016; Tan, 2007) electing students to answer questions in front of the class can cause students to feel insecure because of the individual differences that each student has. Students may feel embarrassed if they are not able to answer questions delivered by the teacher. Foremost, this condition may lead to demotivation and being passive in the learning process which is considered as an unwanted class condition. Students not willing to participate in class is an issue which needs to be avoided in any classes, for it may prevent students to gain benefit from learning and enrich their knowledge. Thus, collaborative learning can be considered as a teaching and learning approach to enhance students' argumentative skill. The purpose of learning collaboratively centers a way for teachers to encourage students studying in a reduced anxiety atmosphere. Therefore, this paper aims to investigate how students' arguments improve through collaborative learning in their native language, bahasa Indonesia.

As stated by Purnomo (2017), the era of IR 4.0 demands teachers to facilitate students in a learning where classroom practices are student centered, contextual, community integrated, collaborative and technology based (as cited in Afrianto, 2018). Thus, collaborative learning should be considered by teachers as a model of teaching strategy in class. In conducting a collaborative learning, teachers may group students in pairs or small team. Grouping can be based on the students' preferences, students' individual differences, or teachers' random choice. In addition, it is the teachers' power in choosing on how to let the students get to work.
As stated by Hernandez (2012) collaborative learning "goes beyond working together" (cited in Gorgônio et al., 2017, p.51). In order to go beyond working together every member of the group must fulfil their roles by willing to participate; sharing ideas and responding to others' ideas in order to reach a conclusion that is agreed by every group member. Moreover, Gerlach (1994) claims that learning collaboratively occurs from each participant's talk (as cited in Babu et al., 2018). In this research, students were given a task, so they could work together by collaborating ideas; brainstorming, creating and sharing possible solutions. Students were not asked to write down sentences, but main ideas on possible accepted solutions agreed by all team members. The task given to the students was a topic related to their own environment, so all students could seriously work together to find the best solution to be applied in real life. Thus, the students could freely use the internet to get real data in supporting their statement. During discussion, the researches moved to one group to another making sure the students were actively participating and writing down main points, not just simply agreeing to one student's idea. In line with Gokhale (1995), through discussions in a small group of students, it may give opportunities to students in enhancing knowledge on a certain issue (as cited in Rodphotong, 2018). Solving a task in a small group help student get a wider knowledge on a certain issue by others personal knowledge combined. Because of the benefit of learning collaboratively, it can be applied in various disciplines, such as science, mathematics, technology, languages, etc.

Questioning is essential in the learning process. In collaborative learning, students work together to answer questions derived from the teacher. Hence, questioning may also occur from other students during group discussion. When sharing ideas in the group, other group members may ask questions for further details before all members come to an agreement on a certain idea. Students learn more from the talks when explaining, giving evidences, expanding details on their own or classmate's opinion. Furthermore, Kristiyanti et al. (2018) mentions that teachers should consider qualitative and analytical questions as effective questions because these sorts of questions may lead to class discussion. Teachers' questions may be classified according to their level of complexity as either higher order thinking questions or lower order thinking questions. "The cognitive level of questions used in the classroom context is determined by both the learning context and the question" (Chen, 2016, p.219). In a classroom setting, applying the concept of thinking skills is influenced by the learning outcomes. Teachers should carefully arrange questions. Even though a question is meant to be a higher order thinking question, but if the question 
relates to what has been taught in class not requiring self-discovery it is regarded as a lower thinking question instead. Higher order thinking skills refers to an individual's ability to make relations and extensions on an available information in order to solve a task or problem (Mitana et al., 2018, p.243). Beatty et al. (2008) states that questions leading to higher order thinking are concluded better than the lower order thinking because the students do more than recalling from memory (as cited in Kristiyanti et al. 2018). Thus, Bloom et al.'s (1956) taxonomy can be considered as a guide for teachers to generate questions of lower and higher thinking skills.

In the 1950s, taxonomy from Bloom et al.
(1956) was established presenting a hierarchy on the cognitive process which comprises of six categories. Bloom and his colleagues ranged knowledge, comprehension and application as lower order thinking skills and analysis, synthesis and evaluation as higher order thinking skills. Bloom et al.' student, Anderson et al. (2001) then changed the terms used by Bloom from noun to verb; knowledge became remember, comprehension became understand, application turned to apply, analysis to analyze, synthesis changed to evaluate, and the highest rank from evaluation to create (Anderson et al., 2001). Figure 1 shows the original and revised taxonomy of Bloom.

\section{Figure 1}

Bloom et al. 's Origin and Revised Taxonomy (Mithana, Muwagga, \& Ssempala, 2018, p. 242)

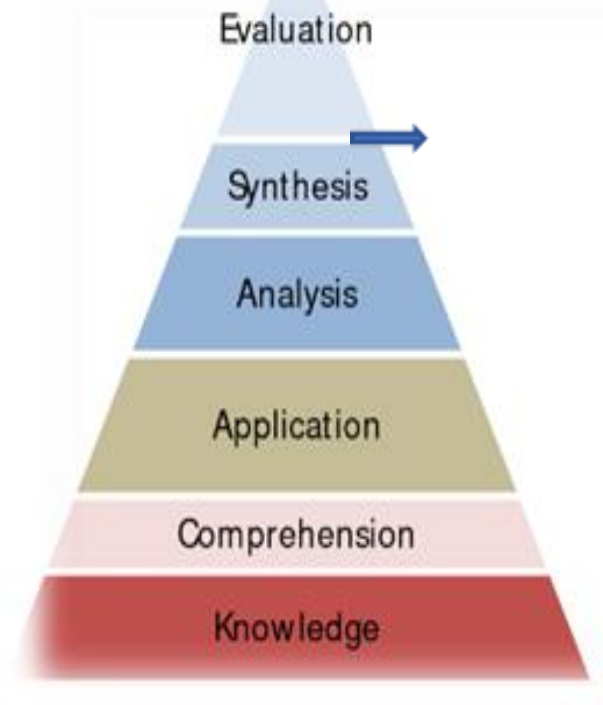

Remember refers to the skill of recalling and recognizing information. In this level, students should be able to answer questions relating to facts, terms, and procedures, for example, responding to instructions of questions on "Who...? What...? When...? Where...? List...!" (Morgan \& Saxton, 1994 as cited in Chen, 2016, p. 218) The next level, understand, demands learners to be able to interpret, exemplify, classify, summarize, infer, compare, and explain on a material being taught by the teacher. The following level, apply, is the skill requiring learners to execute and implement something based on the teaching material. The three other levels belong to the higher order thinking skills, consisting of analyze, evaluate and create. Analyze requires learners to be able in differentiating, organizing, and attributing. Evaluate requires the learner having the ability to critique or cheque something on what is being learnt. The last one, which is the top of higher order thinking skill is create. In this level, it requires learners to generate, plan or produce something. Further in the implementation of the six skills, it is possible for teachers to teach not in order of the Bloom et al.' hierarchy (Mitana, et al, 2018).

Argumentation refers to a verbal activity where the speaker gives reasons in order to justify a delivered standpoint (Eemeren \& Grootendorst, 2004). Argumentation is an important practice because it can give support to learners in reasoning (Kristiyanti, et al, 2018). Being able to construct arguments is crucial for academic achievements and upcoming careers in the $21^{\text {st }}$ century. However, many undergraduate students lack argumentative skills in reasoning, developing and organizing ideas (Meiland, 1983 as cited in Karbach, 1987). In order to improve students' argumentative skills, teachers may use an argument pattern guide known as Toulmin's model of argument or Toulmin's argumentation pattern. Toulmin's model argument comprises of six component parts, namely claim, grounds, warrant, quantifier, backing and rebuttal (Toulmin, 2013). Through this model of argument, argumentation is defined as a set of arguments consisting of claim and reasons related to that claim 
having a purpose to persuade other thoughts on a certain idea. Figure 2 shows the Toulmin's argument model which can be considered as a guide in improving students' arguments.

According to Toulmin (2013), claim is defined as an assertion or a thesis, in other words, the main argument. This component is viewed as a position statement. Data is where the evidence and facts are informed to the audience. Data is an important component because its presence is to support the claim reasonably. Warrant is the assumption linking the data to the claim. A warrant may either be stated or implied. The three components (claim, data and warrant) are considered as the basic part of an argument. However, there are three more component parts which may be added in an argumentation; backing, qualifier and rebuttal. These component parts may be present to support argumentation. The backing give supports to the warrant. Backing can be specific examples leading to a warrant's justification. By adding qualifier to the argument, it limits the claim that it under some conditions it may not be correct or true. Rebuttal, as the last component part may be used giving exceptions that might invalid the claim (Karbach,1987).

\section{Figure 2}

Toulmin's Model of Argument (adapted from Karbach, 1987, p. 85)

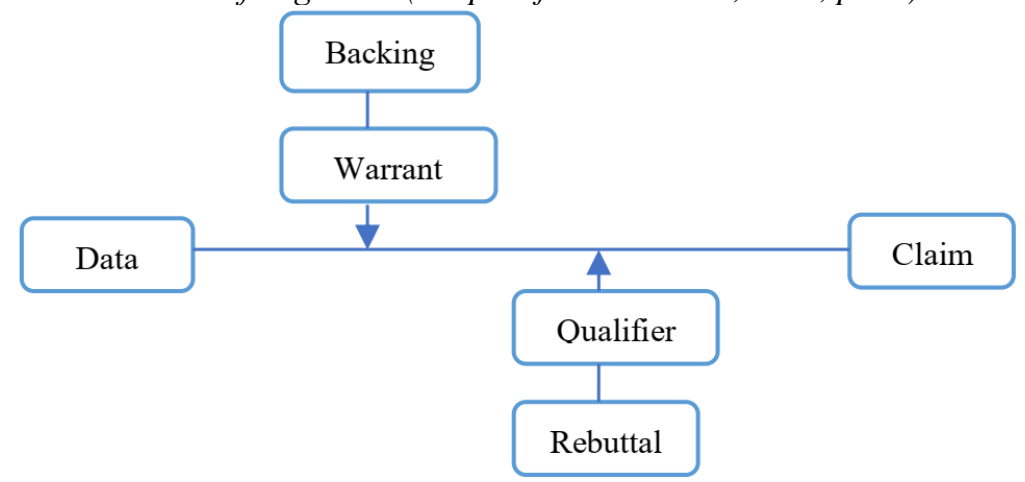

The level of an argument can be seen from the use of component parts (claim, data, warrant, backing, qualifier, rebuttal) An argument that contains many component parts is considered a high-level argument. On the other hand, an argument which contains only one or two component parts if an argument is considered as a low-level argument (Klieger \& Rochsar, 2017).
Scholars have created a tool to be able to examine which level an argument reflects (Erduran et al., 2004; Osbor neet al., 2004; Simon, 2008 as cited in Klieger \& Rochsar, 2017). Table 1 shows the categorization of each 111evel rating from 1 (lowest) to 5 (highest) based on the component parts of arguments used in an argumentation.

Table 1

Argument Levels (Klieger \& Rochsan, 2017)

\begin{tabular}{llc}
\hline \multicolumn{1}{c}{ Component Parts } & Symbols & Level \\
\hline Claim & $\mathrm{C}$ & 1 \\
\hline Claim + Data or Claim + Warrant or Claim + Backing & CD/CW/CB & 2 \\
\hline $\begin{array}{l}\text { Claim + Data + Warrant or Claim + Data + Rebuttal or } \\
\text { Claim + Warrant + Rebuttal }\end{array}$ & CDW/ CDR/ CWR & 3 \\
\hline Claim + Data + Warrant + Backing & & 4 \\
\hline $\begin{array}{l}\text { Rebuttal that includes Claim + Data + Warrant or } \\
\text { Qualifier that includes Claim + Data + Warrant }\end{array}$ & CDWR/CDWQ & 5 \\
\hline
\end{tabular}

This research will be revealing on how students' level of arguments may improve by undergoing some procedures explained in the following section.

\section{METHODS}

The participants of this research were 21 undergraduate students (12 female students and 9 male students) majoring in Japan studies ranging from the age of 16 - 19 years old, enrolling their first month in a university in Indonesia. The participants were students of a class on Discourse. The research was an experimental method of a onegroup pre-test post-test design where pre-test, posttest and a certain stimulus was conducted. This design was chosen to investigate the students' 
argumentative skill progress during the research. The two researches were involved in obtaining data in the class. This research was conducted through a collaborative learning process. Students were grouped randomly into 6 groups, each group consisted of 3-4 students. The purpose of the

\section{Figure 3}

Collaborative Learning

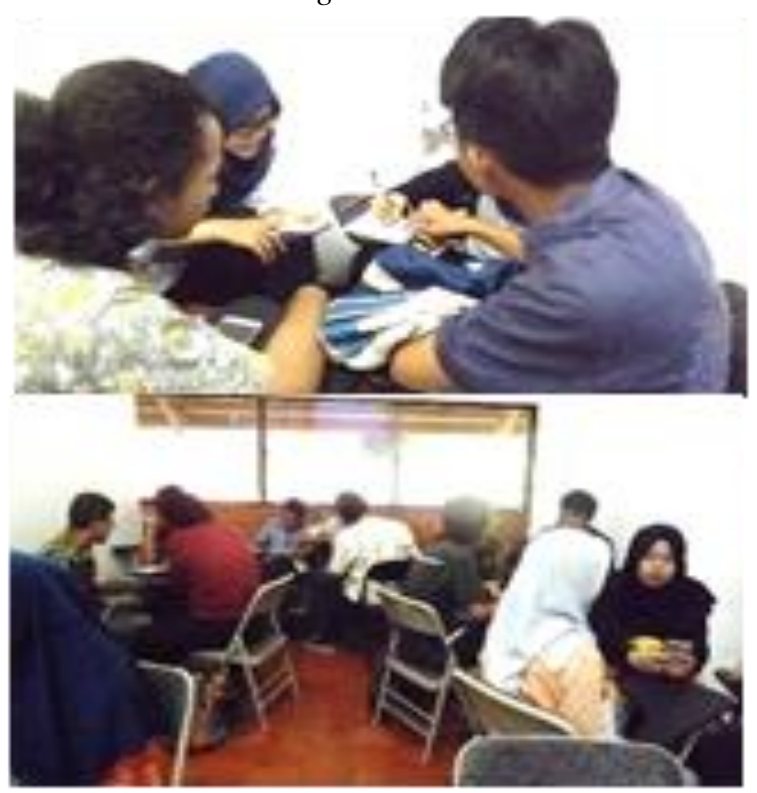

This research procedure consisted of five steps. The first step was the pre-test. In this step, the learners were asked to answer one question related to their thoughts on how to solve pollution for a better and healthier life, a modified question from a question in Indonesia's 2019 presidential debate about environment issue in 2 minutes. The question was chosen because it was familiar to students' knowledge. This step was intended to see how students build their arguments in a problem-solving task as well as to see whether the students made improvements later from the treatment in a collaborative learning context.

Next, the participants watched a video part of Indonesia's 2019 presidential debate (the segment of environment) in duration of approximately 6 minutes. A video show was chosen in this research to promote the industrial revolution of 4.0 where technology was integrated in the teaching and learning process. After the video was shown, the teacher asked higher order thinking questions to activate their skills of analyze and evaluate. The questions were intended to trigger students to use their critical and analytical thinking collaboratively.

In the third step, the researcher gave a mini presentation on Toulmin's argument model as a guide for learners in constructing a strong argumentation. After the mini presentation, learners were asked to create an argumentation collaboratively for a post-test, adapting the question from the pre-test, imagining themselves as a grouping was to create a reduced-stress learning, so all students could actively participate with less anxiety in their group. Figure 3 depicted how the undergraduate students were involved in the learning process.

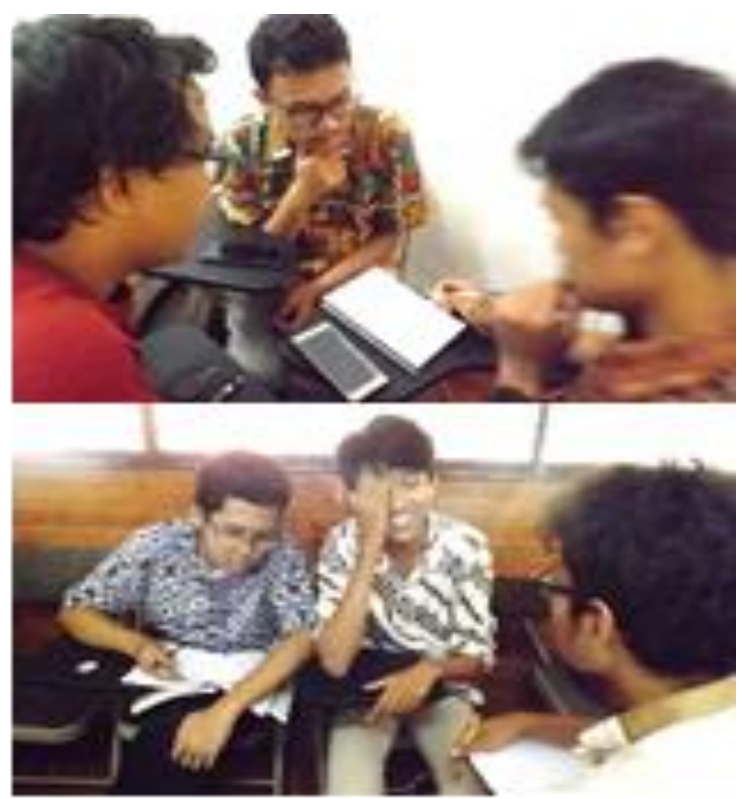

representative from a political party on how they will solve the pollution problem for a better and healthier Indonesia. A duration of 20 minutes were given for the discussion and 2 minutes for delivering responses. Students' arguments were recorded, transcribed and translated for data analysis. Some parts of the activities in this research were uploaded to youtube channel (Filia, 2020). The pre-test and the post-test contained argumentations from 6 groups of students which were then analyzed by the researcher using Toulmin's model of argument. The two researches worked together in analyzing the argumentation by comparing the results of the coding on the component argument parts. The fifth or last step of the research procedure was interpreting the research result.

\section{FINDINGS AND DISCUSSION}

This section provides the findings and discussion of the research consisting of students' argument variation in the pre-test, students' argument variation in the post-test and students' argument improvement through a collaborative learning.

\section{Students' Argument Variation in the Pre-test}

The pre-test was conducted before a given treatment, Toulmin's model argument. The question from the pre-test was "How can you solve the environmental pollution in Indonesia for a better 
and healthier living?" Students were given a duration of 20 minutes to answer the pre-test. Only one member of the group will answer the pre-test. The answers from the pre-test were analyzed by coding the arguments based on the component parts of Toulmin's model of argument, which are claim (C), data (D), warrant (W), qualifier (Q) and rebuttal (R). The two researches did the coding process separately. Then, the coding results were compared.

Based on the findings, only half of the group makes use of data to support the claim and only few groups use warrant to bridge claim and grounds. Table 2 shows the findings of students' argument patterns on the variation usage of argument component parts in the pre-test.

Table 2

Students' Argument Pattern in the Pre-Test

\begin{tabular}{ccc}
\hline Group & $\begin{array}{c}\text { Students' Argument } \\
\text { Pattern }\end{array}$ & Symbols \\
\hline I & Claim & C \\
\hline II & Claim + Data + Warrant & $\mathrm{C}+\mathrm{D}+\mathrm{W}$ \\
\hline III & Claim + Data + Warrant & $\mathrm{C}+\mathrm{D}+\mathrm{W}$ \\
\hline IV & Claim + Data & $\mathrm{C}+\mathrm{D}$ \\
\hline V & Claim & $\mathrm{C}$ \\
\hline VI & Claim & $\mathrm{C}$ \\
\hline
\end{tabular}

Based on the findings in Table 2, not all students are aware that there should be supporting data included in a statement in order to make a claim on a certain issue sound reasonable.

Before the treatment was given group I, V and VI made argumentation consisting only of claims. The groups mainly provided series of possible solutions without specific data related to the made claims. The following is an example of the argumentation which from the beginning until the end of the argumentation only consisted of claims.

"Our strategies are related to our surrounding environments. The first, is to reduce plastic bags. The second is to provide different sorts of trash bins, so sorting becomes easier. Next, the BEM FIB (the legislative of the Faculty of Humanities) has already socialized the change from plastic straws into stainless ones. Then, other steps out of the faculty is the presence of a University bus as a public transport. So, it can reduce pollution. After that the last point is that people should smoke in a provided smoking area. In FIB, people like to smoke anywhere. So, it should be a concern for a more friendly environment." (transcription of Group I's pre-test)

Even though the students gave many possible solutions containing of facts, the argumentation were not followed by supporting data to strengthen reasons for the statement. This kind of pattern is considered very weak or the lowest level of arguments (Klieger \& Rochsan, 2017).

Group IV, however, showed that some students were already aware that there should be more than just claims in an argumentation. In the argumentation made by group IV, three kinds of issues were delivered with only two claims that was provided by supporting data. The following is a part of group IV's argumentation consisting evidence of percentage of population were mentioned to support the claim. Unfortunately, sources from their claims were not mentioned. The following, shows a part of group IV's effort in generating their argument.

“... Our party has some suggestions. First, reduce the use of private transportation. Jakarta is the city most visited by $46 \%$ of people in Indonesia donating a big amount of $\mathrm{CO} 2$ harming the environment quality..." (transcription of Group IV's pre-test).

The other groups, group II and III made more efforts in their argumentation by providing a warrant to support their claim and data. As seen in the following part of group III's pre-test, the warrant linked the claim with the data.

"... So, the second is by using plants, one of them is sansevieria (claim). Sanseviera can reduce CO2 in our surroundings because it can absorb CO2 (data) So, we will get fresh air from our surroundings (warrant) ... (transcription of Group III's pre-test).

The three variation patterns found in the pretest mentioned previously, $\mathrm{C}, \mathrm{C}+\mathrm{D}$, and $\mathrm{C}+\mathrm{D}+\mathrm{W}$ shows that before the treatment was given not all students were aware of giving argument supported by justification. This finding on students' lack of argumentation skills is in line with Skuomos and Hatzinikita (2008) research (cited in Syerliana et al., 2018). In order to see any improvements from the given treatment in this research, students' argument variation patterns in the pre-test will be compared with the findings from the student's argument variation in the post-test.

\section{Students' argument variation in the post-test}

In the treatment, conducted after the pre-test, students were introduced to Toulmin's model of argument. Then, students were asked to analyze some part of arguments found in the Indonesia's 2019 presidential debate video by class discussion to make sure students understood well component parts of an argument. Throughout the treatment, students were faced to use thinking skills' ability, remember, understand, apply and analyze. After the treatment of this research was accomplished, the undergraduate students were given another opportunity to construct arguments in the post-test. From this activity, students were intended to use their higher thinking skills, analyze. The question in the post-test was modified from the pre-test, "Imagine your team as representatives from a political party. How will your party solve Indonesia's environmental pollution for a better and healthier living?"

During the group discussion of the post-test, the researchers moved to each group to another to monitor the students. Students were sharing ideas, 
offering opinions in adding argument component parts to the claims agreed by the group rather than compiling ideas from each group member which was the main goal of the collaboration. In order to maximize the use of component argument parts, students were allowed to access the internet in class. The usage of the internet was essential in the learning because it provides relevant data that could be used to build an argument. Students' must work together to manage what data to choose to support their claims. In addition, students were not given a strict rule in using Toulmin's 6 component parts of argument. Students could freely use any component parts needed in order to construct argumentation. Table 3 reveals five different patterns of students' argument found in the post-test.

Table 3

Students' Argument Pattern in the Post-Test

\begin{tabular}{ccc}
\hline Group & Students' Argument Pattern & Symbols \\
\hline I & Claim + Data + Warrant + Rebuttal & C+ D +W+R \\
\hline II and VI & Claim + Data + Rebuttal & $\mathrm{C}+\mathrm{D}+\mathrm{R}$ \\
\hline III & Claim + Data + Backing+ Rebuttal & $\mathrm{C}+\mathrm{D}+\mathrm{B}+\mathrm{R}$ \\
\hline IV & Claim + Data + Warrant + QualifierBacking & $\mathrm{C}+\mathrm{D}+\mathrm{W}+\mathrm{Q} \mathrm{B}$ \\
\hline V & Claim + Data +Warrant & $\mathrm{C}+\mathrm{D}+\mathrm{W}$ \\
\hline
\end{tabular}

As seen from the five variations in Table 3 , the students became aware that there should be more than a just a claim in an argument. This could be proven from the use of other component parts like data, warrant, rebuttal, qualifier and backing.

In addition, based on the findings, there were two groups that used the same pattern of argument component parts, consisting of claim, data, and rebuttal. As seen in group VI's argumentation, rebuttal was used to depict a condition that might happen to support a claim which was then followed by data as support.

“... We must also establish and uphold a strict policy towards the citizens' rights in health and appropriateness. Their residential area will be better and healthier if they have high awareness towards a good knowledge on waste disposal. Giving fines to people who litters and giving socialization on trash bins like what has been conducted in Japan which are adjusted based on the ages of the citizens can be adapted in Indonesia." (post-test of group VI)

Group $\mathrm{V}$ also used three kinds of component parts of argument, but differently. This group used warrant instead of rebuttal in order to link claims and data of their opinion.

"The first thing we will do is to establish a policy on land clearing, especially in forests (claim). As we know, there have been illegal loggings in the forests, such as in Sumatra (data). We want to give efforts to direct the policy where we can tighten the regulations in land clearing, so there will be no illegal land clearing anymore (claim). We will give heavy punishments to those who are irresponsible in illegal land clearing (warrant)..." (post-test of group V)

Other groups, group I, IV and V, used more argument component parts than group II, III and VI. In the last part of group III's argumentation as followed, students made effort to add backing and rebuttal in supporting their claim that was justified by data. The usage of backing and rebuttal for the closing part of the argumentation emphasizes that the claim is important to be considered by the audiences.

"... The last is about the littering regulation (claim). It is because, there are low awareness about the trashes around us (data). For example, someone sees a pile of trash, but they don't do anything, they don't care, "it's not my trash" (backing). If everyone has the same thoughts, the trashes will be scattered everywhere (rebuttal)." (post-test of group III).

Group IV made more effort in justifying their argument by using claim, data, warrant and qualifier. Surprisingly, this group used warrant more than once provided in each claims. The group intended to generate claims accompanied by another component part of argument, either data, warrant, backing or qualifier. As seen in the first part of the argument, a qualifier was used with claims, data and warrant.

".... The first is to have a clear SOP (claim). Because Indonesia is known to have regulations that are not clear, such as on littering and illegal logging (data). In our clear SOP, the society will have a clear view on how to deal with the environmental pollution, it can make them understand on what to do, like to prevent or recover the environment also handling the existed pollution also recovery (qualifier). After a clear SOP is made, then there should be an outspread of awareness towards the society and children through early education and school (claim). Actually, there is school subject in school namely PMK., but the culture keeping the environment is still seen very low from Indonesian children (data). So, it is just theory with no action (warrant). " (post test of group IV)

As for group I, the group made effort to use rebuttal with claim, data and warrant. In the following part of argumentation by group I, similar to group IV, different kinds of component part were used after claims. 
“...It's just useless for a law-enforcement if there's no action from us (claim). Even how heavy it is, or even how big the fine is, but if we don't want to take action, we think it's very useless (warrant). .. They give socialization based on the citizen's age, from children, adults to elderly, they are given different kinds of socializations, not just any socializing (claim). But, in Indonesia, the citizens do not care, there's no change (data). ... So, parents can remind the young to not litter (rebuttal)..." (post-test of group I)

It could be concluded that the students were able to make use of the component parts from Toulmin's argument pattern model. Based on the post-test findings, the usage of rebuttal in the closing of argument were more favorable by the students compared to the usage of qualifier because it was used by four groups out of six. Qualifier, however, was less used by the students. Reasons on the students' preferences on using the argument component parts were not studied.

\section{Students' argument level improvements}

Throughout the discussion of 20 minutes for the post-test, students were participating through talks in groups on constructing good quality of arguments. During the discussion, students were agreeing, disagreeing and generating questions in order to organize ideas from all group members into one. In the groups, the students were recalling information, applying the component parts of argumentation and analyzing and evaluating their own component parts of argumentation to produce a collaborated argumentation for the final task.

In order to conclude students' improvements in their argumentation, the argument levels of the pretest were compared with the post-test based on the argument level scale from Klieger and Rochsar's (2017) mentioned in the introduction section. Based on the result, the undergraduate students were more aware in giving supports in justifying their claims. From the findings, there were five variations of argument components in the argumentation post-test $(\mathrm{C}+\mathrm{D}+\mathrm{W}, \mathrm{C}+\mathrm{D}+\mathrm{R}$ (2 groups), $\mathrm{C}+\mathrm{D}+\mathrm{B}+\mathrm{R}$, $\mathrm{C}+\mathrm{D}+\mathrm{W}+\mathrm{R}$ and $\mathrm{C}+\mathrm{D}+\mathrm{W}+\mathrm{Q}$ ) which shows that the students improved their argument level as shown in Table 4.

After treatment, there were great changes on the component parts of argument by some groups. Compared to the pre-test, all groups were able to give claims supported by data. None of the arguments consisted of claim alone, but supported with other component argument parts, such as data, warrant, backing, qualifier and rebuttal. As seen in Table 4, 5 out of 6 groups were able to improve their argument levels by being able to add more than one component part in their argument. Three groups reached the highest level of the argument level that consisted the usage of four argument component parts with the patterns of CDWR, CDBR and CDWQ. Meanwhile, the other three groups reached the middle level or level 3 with the pattern of CDW and CDR.

Table 4

Students' Argument Levels in Pre-Test and Post-Test

\begin{tabular}{clclc}
\hline \multirow{2}{*}{ Group } & \multicolumn{2}{c}{ Pre-test } & \multicolumn{2}{c}{ Post-test } \\
\cline { 2 - 5 } & Component Argument & Argument Level & Component Argument & Argument Level \\
\hline I & $\mathrm{C}$ & 1 & $\mathrm{C}+\mathrm{D}+\mathrm{W}+\mathrm{R}$ & 5 \\
\hline II & $\mathrm{C}+\mathrm{D}+\mathrm{W}$ & 3 & $\mathrm{C}+\mathrm{D}+\mathrm{R}$ & 3 \\
\hline III & $\mathrm{C}+\mathrm{D}+\mathrm{W}$ & 3 & $\mathrm{C}+\mathrm{D}+\mathrm{B}+\mathrm{R}$ & 5 \\
\hline IV & $\mathrm{C}+\mathrm{D}$ & 2 & $\mathrm{C}+\mathrm{D}+\mathrm{W}+\mathrm{Q}$ & 5 \\
\hline V & $\mathrm{C}$ & 1 & $\mathrm{C}+\mathrm{D}+\mathrm{W}$ & 3 \\
\hline VI & $\mathrm{C}$ & 1 & $\mathrm{C}+\mathrm{D}+\mathrm{R}$ & 3 \\
\hline
\end{tabular}

The argument level of group I jumped from level 1 to level 5. This group made the most changes compared to other groups, that is an addition of 4 component parts of argument. Group III, V and VI made an additional 2 component parts in their posttests compared to their pre-test. Group IV was the only group that chose to add a qualifier in their argument and made 3 additional component parts in their arguments. Even though Group II stayed in the same argument level, but this group managed to learn how to use a different component part of argument; from Claim + Data + Warrant to Claim + Data + Rebuttal.

Furthermore, based on the findings shown in Table 4, students achieved to use their thinking skills from remember to analyze in generating arguments. Students remembered Toulmin's model of argument part, were able to understand the differences of the parts, were able to apply different kinds of component parts and were able to analyze their own argument parts through collaborative learning. In sum, through the practice of collaborative learning, students could increase their skills in giving argumentations, for there were found differences on students' variation of argument pattern and argument level.

\section{CONCLUSION}

Developing and organizing ideas into an argument are mostly found difficult by undergraduate students to accomplish. However, they are vital skill to be mastered for academic achievements. The industrial revolution of 4.0 era calls for education which 
supports student centered, contextual, community integrated, collaborative and technology-based learning. Hence, teachers should facilitate students with a stimulus that can guide students in generating arguments. Therefore, collaborative learning can be considered as a classroom practice in a way to improve students' arguments. By collaborative learning, students have the opportunity to enhance their thinking skills from provided stimulus. In this research, students watched a video part of the presidential debate as a visualization on how arguments can be produced, consisting of a standpoint and relevant facts as the support. Toulmin's model of argument consisting of claim, data, warrant, backing, rebuttal and qualifier are component parts taught explicitly to be as a guide in constructing arguments. Questions were also facilitated to trigger students thinking skills. Based on the research, students were able to process their cognitive in remembering, understanding, applying and analyzing throughout the collaborative learning.

In fact, through collaborative learning, students become more aware on more component parts of an argument. Based on the findings, five variations of component parts were produced by the students, they are (1) Claim + Data + Warrant $(C+D+W)$, (2) Claim + Data + Rebuttal $(\mathrm{C}+\mathrm{D}+\mathrm{R})$, (3) Claim + Data + Backing + Rebuttal $(\mathrm{C}+\mathrm{D}+\mathrm{B}+\mathrm{R}),(4)$ Claim + Data + Warrant + Rebuttal $(\mathrm{C}+\mathrm{D}+\mathrm{W}+$ $\mathrm{R})$, and (5) Claim + Data + Warrant + Qualifier (C + $\mathrm{D}+\mathrm{W}+\mathrm{Q})$. Students show to have different preferences on whether to imply or state warrants in their argument. In addition, rebuttal is preferred more than backing and qualifier. Further research can be conducted to reveal reasons on the student's preferences in stating or implying warrants. Moreover, other native languages or second languages can be considered for further researches.

As conclusion, this research can be considered as a teaching framework to fulfill the demand of classroom practices in the industrial revolution of 4.0. Collaborative learning is proved to be applicable as a learning model that can improve student's argument quality taping to lower thinking skills (remember, understand and apply) and a higher order thinking skill (analyze) in the learning process. However, students did not achieve to tap into a more higher order thinking skill from analyze, which are evaluate and create. Further research may be conducted for a deeper study on students' reasons on their preference patterns when stating an argumentation.

\section{ACKNOWLEDGMENT}

This work was supported by Universitas Indonesia's Research Grant (PITMA B 2019) managed by Direktorat Riset dan Pengabdian kepada Masyarakat, Universitas Indonesia (DRPM UI).

\section{REFERENCES}

Afrianto. (2018). Being a professional teacher in the era of industrial revolution 4.0: Opportunities, challenges and strategies for innovative classroom practices. English Language Teaching and Research, 2(1), 1-13. http://103.216.87.80/index.php/eltar/article/vie w/102675

Amielia, S.H., Suciati, \& Maridi. (2018). Enhancing students' argumentation skills using an argument driven inquiry-based module. Journal of Education and Learning, 12(3), 464-471.

http://dx.doi.org/10.11591/edulearn.v12i3.804 2

Anderson, L., Krathwohl, D. R., Airasian, P. W., Cruikshank, K. A., Mayer, R. E., Pintrich, P. R., Raths, J., \& Wittrock, M. C. (2001). A taxonomy for learning, teaching and assessing: A revision of Bloom taxonomy of educational objectives. Longman.

Babu, G., Suresh, P., \& Pariventhan, K. (2017). Enhancement of learning through collaborative learning techniques. New Man International Journal of Multidisciplinary Studies, 4(9), 29 38.

Bloom, B., Englehart, M., Furst, E., Hill, W., and Krathwohl, D. (1956). Taxonomy of educational objectives: The classification of educational goals. Longman.

Chen, M. H. (2016). Theoretical framework for integrating higher order thinking into L2 speaking. Theory and Practice in Language Studies, 6(2), 217-226. https://doi.org/10.17507/tpls.0602.01

Eemeren, F.H.V. \& Grootendorst, R. (2004). A systematic theory of argumentation: The pragma-dialetical approach. Cambridge University Press

Filia. (2020, September 7). Data "Improving students' arguments through collaborative learning" [Video]. Retrieved from https://youtu.be/iPOEv-hq0V8

Gorgônio, F. L., Silva, Y. K. N., Vale, K. M. O., \& Silva, H. M. (2017). Grouping students for cooperative and collaborative learning: Challenges and trends in virtual learning environments. EDUNINE, 2, 51-55. https://edunine.eu/edunine2017/proc/works/33 .pdf

Karbach,J. (1987). Using Toulmin's model of argumentation. Journal of Teaching Writing, 6(1), 81-91. https://134.68.190.10/index.php/teachingwriti ng/article/download/821/810

Klieger, A. \& Rochsar, A. (2017). Impartation of argumentation skills: Impact of scaffolds on the quality of arguments. Journal of Advances 
in Education Research, 2(3), 183-190. https://dx.doi.org/10.22606/jaer.2017.23006

Kristiyanti, T. P., Ramli, M., \& Ariyanto, J. (2018). Improving the argumentative skills of high school students through teacher's questioning techniques and argumentative assessment. Journal of Physics: Conference Series, 1013, 012012. https://doi.org/10.1088/17426596/1013/1/012012

Mitana, J. M. V., Muwagga, A. M., \& Ssempala,C. (2018). Assessment of higher order thinking skills: A case of Uganda primary leaving examinations. African Educational Research Journal, 6(4), 240-249. https://doi.org/10.30918/AERJ.64.18.083

Rodphotong, S. (2018). The effectiveness of collaborative learning to enhance English communicative competence: A case study of the first-year students at Thepsatri Rajabat University. International Journal of Pedagogy and Teacher Education, 2, 137-144. https://doi.org/10.20961/ijpte.v2i0.25174

Tan, Z. (2007). Questioning in Chinese university EL classrooms: What lies beyond it? RELC Journal, 38(1), 87-103. https://doi.org/10.1177/0033688206076161

Toulmin, S.E. (2003). The uses of argument. Cambridge University Press.

Simon, S. (2008). Using Toulmin's Argument Pattern in the evaluation of argumentation in school science. International Journal of Research \& Method in Education, 31(3), 277289 , https://doi.org/10.1080/17437270802417176

Suhartoyo, E., Mukminatien, N., \& Laksmi, E.D. (2015). The effect of Toulmin's model of argumentation within TWPS strategy on students' critical thinking on argumentative essay. Jurnal Pendidikan Humaniora, 3(2). 143-153. http://journal.um.ac.id/index.php/jph/article/vie w/4856

Syerliana, L., Muslim, \& Setiawan, W. (2019). Argumentation skill profile using "Toulmin Argumentation Pattern" analysis of high school student at Subang on topic hydrostatic pressure. Journal of Physics: Conference Series 1013, 012031. https://doi.org/10.1088/17426596/1013/1/012031

Widodo, A., Waldrip, B., \& Herawati, D. (2016). Students' argumentation in science lessons: A story of two research projects. Jurnal Pendidikan IPA Indonesia (JPII), 5(2), 199208. https://journal.unnes.ac.id/nju/index.php/jpii/ar ticle/view/5949 